\title{
Increased intrathecal inflammatory activity in frontotemporal dementia: pathophysiological implications
}

\author{
M Sjögren, S Folkesson, K Blennow, E Tarkowski
}

J Neurol Neurosurg Psychiatry 2004;75:1107-1111. doi: 10.1136/jnnp.2003.019422

See end of article for authors' affiliations

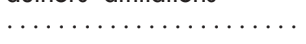

Correspondence to: Dr M Siögren, Department of Neuropsychiatry, Sahlgrenska University Hospital/Mölndal, SE431 80 Mölndal, Sweden; magnus.sjogren@ vregion.se

Received 23 May 2003 Revised 25 October 2003 Accepted

1 November 2003

\begin{abstract}
Objective: Immunological mechanisms may be part of the pathophysiological mechanisms in frontotemporal dementia (FTD), but hitherto only vague evidence of such mechanisms has been presented. The aim of this study was to compare the cerebrospinal fluid (CSF) levels of the pro-inflammatory cytokines interleukin (IL)- $1 \beta$ and tumour necrosis factor (TNF)- $\alpha$, and the anti-inflammatory cytokine transforming growth factor (TGF)- $\beta$ in patients with FTD and normal controls. Furthermore, serum levels of TNF- $\alpha$, TGF$\beta$, and IL- $1 \beta$ were measured in FTD patients.

Methods: The CSF levels of IL-1 $\beta$, TNF $\alpha$, and TGF- $\beta$ were measured using ELISA in 19 patients with FTD and 24 sex and age matched healthy controls.

Results: The CSF levels of TNF- $\alpha$ (FTD $0.6 \mathrm{pg} / \mathrm{mL}$ (median: lower, upper quartile 0.3, 0.7); controls: $0.0 \mathrm{pg} / \mathrm{mL}(0.0,0.0) ; p=0.008)$ and TGF- $\beta$ (FTD $266 \mathrm{pg} / \mathrm{mL}(157,371)$, controls: $147 \mathrm{pg} / \mathrm{mL}(119$, 156); $p=0.0001$ ) were significantly increased in FTD patients compared with controls. No correlations were found between CSF and serum levels of the cytokines. In the controls, but not in the FTD patients, a positive correlation was found between the CSF levels of TGF- $\beta$ and age $(r=0.42, p<0.05)$. No correlation was found between any of the cytokines and degree of brain atrophy or white matter changes. No differences between the groups were found for age, gender, or CSF/serum albumin ratio.

Conclusions: The results suggest an increased intrathecal production of both pro- and anti-inflammatory cytokines in FTD. As no correlations were found with the albumin ratio, and no correlations between CSF and serum levels of the cytokines were found, these changes in the CSF cannot be explained by a systemic overproduction of cytokines.
\end{abstract}

$\mathrm{F}$ rontotemporal dementia (FTD) is one of the most common types of primary degenerative dementia. In post-mortem investigations on demented populations, the prevalence of FTD has been estimated at 3-10\%. ${ }^{1-3}$ In the pre-senium, FTD is probably the second most common primary degenerative dementia, as its onset occurs usually before the age of 65 years. ${ }^{4}$

The aetiology of FTD is unknown in most cases, but an involvement of tau and neurofilament proteins, both cytoskeleton proteins, has been suggested. ${ }^{5}{ }^{6}$ Studies on brain tissue have found pathological tau proteins in $\mathrm{FTD}^{7}$ but the cerobrospinal fluid (CSF) levels of tau are usually normal or only slightly increased in this disorder. ${ }^{8-11}$ In hereditary forms of FTD, mutations have been found in the tau gene on chromosome $17 .{ }^{12}$ However, the frequency of these mutations seems to be low in the FTD population. ${ }^{13} 14$

Another possibility is that autoimmune mechanisms are involved in the pathophysiology of FTD. Several studies ${ }^{15-23}$ have found evidence of an ongoing inflammatory process in Alzheimer's disease (AD). That such a process may also occur in FTD has only tentatively been suggested, ${ }^{24}$ and no thorough scientific investigations into the matter have yet been carried out. However, increased serum levels of antibodies towards gangliosides have been found in FTD patients, ${ }^{25}$ which suggests that autoimmunity and inflammation may be part of the pathophysiological mechanisms of FTD.

The objective of the present study was to analyse the CSF levels of the cytokines tumour necrosis factor (TNF)- $\alpha$, interleukin (IL)-1 $\beta$, and transforming growth factor (TGF) $-\beta$ in FTD patients and healthy controls. Serum levels of the cytokines were also measured in FTD. Our starting point was that any difference between the groups would support the notion that underlying inflammation contributes to the development of FTD.

\section{MATERIALS AND METHODS}

\section{Subjects}

Nineteen patients with clinical FTD (age range at investigation 47-80 years) and 24 controls (age range at investigation 50-83 years) were included in the present study. Their characteristics are summarised in table 1.

The patients had been admitted for clinical evaluation of dementia and were evaluated in the neuropsychiatric diagnostic ward at the Institute of Clinical Neuroscience, Sahlgrenska University Hospital, Mölndal, Sweden. To be included in the present study, patients had to be 80 years of age or younger and have mild or moderate dementia. Excludsion criteria were a clinical diagnosis of $\mathrm{AD}$, vascular dementia, unspecified dementia, or mixed dementia (for example, $\mathrm{AD}$ and vascular dementia concomitantly present); a history of severe psychiatric disease (such as schizophrenia or manic depressive disorder), chronic alcoholism, or distinct nondegenerative neurological disease (for example, normotensive hydrocephalus); a history of severe head injury, severe infections in the central nervous system, systemic diseases (such as malignant tumours), or secondary causes of dementia (such hypothyreosis), as defined in the DSM-III- ${ }^{26}$ or by biochemical criteria. All included patients underwent a thorough clinical evaluation, including medical history, physical, neurological and psychiatric examinations, laboratory screening tests of blood, routine analysis of the CSF (for example, cytology), ECG, chest $x$ ray, EEG, and CT or MRI of the brain. An investigation of the cerebral blood flow, using single photon emission computerised tomography, was conducted in most patients.

Abbreviations: $A D$, Alzheimer's disease; CSF, cerebrospinal fluid; FTD, frontotemporal dementia; IL, interleukin; MMSE, Mini Mental State Examination; TE, echo time; TGF, transforming growth factor; TNF, tumour necrosis factor; TR, repetition time; WMC, white matter changes 
Table 1 Clinical characteristics

\begin{tabular}{|c|c|c|c|c|c|c|c|}
\hline Subjects & $n$ & Sex (M:F) & Age (years) & $\begin{array}{l}\text { Age at onset } \\
\text { of dementia (years) }\end{array}$ & $\begin{array}{l}\text { Duration } \\
\text { of dementia (years) }\end{array}$ & Albumin ratio & MMSE score \\
\hline FTD & 19 & $6: 13$ & $66.2(8.0)$ & $61.0(8.0)$ & $5.2(3.9)$ & $6.4(3.0)$ & $17.1(5.0)$ \\
\hline Controls & 24 & $7: 17$ & $68.0(7.0)$ & - & - & $5.1(1.5)$ & $29.1(0.8)$ \\
\hline
\end{tabular}

FTD was diagnosed according to the Lund/Manchester criteria. ${ }^{27}$ All patients with FTD presented with a predominant frontal lobe syndrome, which has been described previously. ${ }^{28}$ Only mild, insignificant white matter changes (WMC) were found on CT or MRI of the brain in the FTD patients and none of these patients had any signs of infarcts. The EEG patterns of the FTD patients were normal or showed only mild changes.

All clinical diagnoses were made by investigators blinded to the results of the biochemical analyses and vice versa. None of the patients was being treated for dementia (for example, with cholinesterase inhibitors). Four patients with FTD were being treated with selective serotonin reuptake inhibitors and two were being treated with neuroleptics.

In the demented patients, the degree of cognitive impairment was evaluated using the Mini Mental State Examination (MMSE). The grading of dementia was made in accordance with recommendations given in the DSM-III-R.

For control purposes, CSF samples from 24 healthy individuals without any psychiatric, neuropsychiatric, or neurological diseases were used to establish the normal levels of cytokines.

The ethics committee of Göteborg University approved the study. All the patients (or their nearest relatives) and controls gave their informed consent for participation in the study, which was conducted in accordance with the provisions of the Helsinki Declaration.

\section{CSF analyses}

Lumbar puncture was performed at the L3/L4 or L4/L5 interspace. The first $12 \mathrm{~mL}$ of CSF were collected in polypropylene tubes and gently mixed to avoid gradient effects. At the same time, a serum sample was taken. All CSF samples with more than 500 erythrocytes/ $\mu \mathrm{L}$ were excluded. The CSF and serum samples were centrifuged at $2000 \mathrm{~g}$ for $10 \mathrm{~min}$ utes to eliminate cells and other insoluble material. Aliquots were then stored at $-80^{\circ} \mathrm{C}$ until biochemical analysis.

Quantitative determination of serum and CSF albumin was performed by nephelometry, using the Behring Nephelometer Analyzer (Behringwerke AG, Marburg, Germany). The CSF/ serum albumin ratio was calculated as CSF albumin (mg/L) divided by serum albumin $(\mathrm{g} / \mathrm{L})$ and was used as the measure of blood-brain barrier function. The normal value is $<10$; one of the FTD patients had an albumin ratio value just above 10. All in the control group had normal values.

The CSF and serum levels of TNF- $\alpha$, IL- $1 \beta$, and TGF- $\beta$ were estimated using ELISA (Quantikine R\&D Systems, Minneapolis, MD, USA), as previously described. ${ }^{21}{ }^{22}$ The detection levels of TNF- $\alpha$, IL- $1 \beta$ and TGF- $\beta$ were 0.2 . 0.1 , and $7 \mathrm{pg} / \mathrm{mL}$ respectively. Values below the detection levels were considered to be negative.

CT

All CT scans were performed without contrast enhancement and with $10 \mathrm{~mm}$ continuous slices through the cerebrum and $5 \mathrm{~mm}$ slices through the cerebellum. Seven FTD patients underwent CT examinations, all of which were performed on a Siemens Somatom Plus. All CT scans were examined and rated by radiologists without knowledge of the clinical diagnoses.

The method used for rating atrophy and WMC was initially developed for CT but is also useful for MRI scans and has been described previously. ${ }^{29}$ For ratings of the intensity of atrophy, the images were divided into six separate regions: frontal cortical, temporal cortical, parietal cortical, occipital cortical, frontal central (ventricles), and occipital central. The degree of atrophy was rated for each region using a 4 point scale: $0=$ no atrophy, $1=$ slight atrophy, $2=$ moderate atrophy, and $3=$ severe atrophy. For rating of the intensity of WMC (lesions), the white matter was divided into three separate regions: frontal (mainly around the frontal horns), paraventricular/parietal (defined as parietal and/or paraventricular), and occipital white matter. The degree of WMC was rated for each region using a 4 point scale: $(0=$ no lesions, $1=$ mild lesions, focal lesions, 2 =beginning confluent lesions, $3=$ severe extensive lesions). The presence, locations, and sizes of infarcts were also evaluated.

\section{MRI}

MRI was performed on a $1.0 \mathrm{~T}$ magnet (Siemens Magnetom Impact, Germany), and conventional spin echo sequences were used. These included proton density weighted and T2 weighted images (repetition time (TR)/echo time (TE) 2250/ 20-80 ms) and Tl weighted axial scans (TR/TE 500/15 ms). In eight of the 15 FTD patients that were quantitatively evaluated, the brain was examined using contiguous slices with $6 \mathrm{~mm}$ slice thickness in the transversal and sagittal planes. The scans were evaluated by experienced neuroradiologists, who were blinded to the clinical evaluations. Ratings of intensity of cortical atrophy and WMC were performed similarly to the CT scans. ${ }^{29}$

\section{Statistical analysis}

As one of the effect variables (CSF TNF- $\alpha$ ) was not normally distributed and a log transformation, in spite of yielding a normally distributed variable, resulted in zero values for several cases, it was decided to use the Mann-Whitney U test to investigate differences between FTD patients and controls. However, in order to investigate the possible effect of covariates, two way analysis of covariance was also used. In this, TNF- $\alpha$ was first log transformed to meet the demands of normal distribution. Two way analysis of covariance was then performed with diagnostic groups and gender as factors, CSF levels of TNF- $\alpha$, IL- $1 \beta$, and TGF- $\beta$ as effect variables, and age and albumin ratio as co-factors. Factors and covariates that did not contribute to the variance were excluded and the analysis redone. Pearson product moment correlation was also calculated on normally distributed variables (log transformed CSF TNF- $\alpha$ ). A p value $<0.05$ was considered statistically significant. Fisher's exact test was used to analyse differences in proportion.

In order to investigate correlations between the CSF levels of TNF- $\alpha$, TGF- $\beta$, or IL- $1 \beta$ and measures of cerebral atrophy and WMC, Spearman rank correlation test was used. This was also used for correlations between CSF and serum levels of the cytokines. 


\section{Demographics}

There were no significant differences in age, gender, or CSF/ serum albumin ratio between the groups (see table 1 ).

\section{RESULTS}

From the two way analysis of covariance, it was concluded that there was no effect on the variance in the effect variables (TNF- $\alpha$, IL-1 $\beta$, and TGF- $\beta$ in the CSF) for gender, age, or albumin ratio. A significant effect was found only for diagnosis $(\mathrm{F}=9.3, \mathrm{df}=3, \mathrm{p}=0.0001)$.

Fifteen of the 19 FTD patients but only 5 of the 24 controls had detectable levels of TNF- $\alpha$ in the CSF $(p=0.001)$. The CSF levels of TNF- $\alpha$ were significantly increased in the FTD patients compared with the controls (mean (median: lower, upper quartile): FTD $0.6 \mathrm{pg} / \mathrm{mL}(0.3,0.7)$; controls $0.0 \mathrm{pg} / \mathrm{mL}$ $(0.0,0.0) ; p=0.008)$.

Detectable CSF TGF- $\beta$ levels were found in all included individuals; however, eleven of the 19 FTD patients had a higher level of CSF TGF- $\beta$ compared with the maximum level among the control individuals. CSF TGF- $\beta$ was significantly increased in FTD patients compared with controls (FTD $266 \mathrm{pg} / \mathrm{mL}$ (157, 371), controls: $147 \mathrm{pg} / \mathrm{mL}$ (119, 156); $\mathrm{p}=0.0001)$.

Only one FTD patient and no control individual had a detectable level of CSF IL-1 $\beta$. No significant difference in CSF IL- $1 \beta$ levels was found between FTD patients and controls.

In the control group, but not in the FTD group, there was a positive correlation between age and CSF TGF- $\beta(\mathrm{r}=0.42$; $\mathrm{p}<0.05$ ). No significant correlation was found in either group between the degree of dementia, as measured with MMSE, and the CSF levels of the cytokines. No correlations were found with duration of disease or treatment with SSRI or neuroleptics in the FTD group (fig 1).

No correlations were found between TNF- $\alpha$, TGF- $\beta$, or IL$1 \beta$ in the CSF and quantitative measures of cerebral atrophy or WMC.(table 2). Furthermore, no significant correlations were found between CSF and serum levels of the cytokines in FTD (for TGF- $\beta, r=-0.14$, NS; for TNF- $\alpha, r=0.41$, NS). The serum levels of the cytokines in FTD were: TNF- $\alpha 3.4 \mathrm{pg} / \mathrm{mL}$ $(2.6,3.9)$ and TGF- $\beta 19.3 \mathrm{ng} / \mathrm{mL}$ (13.8:24.0) (mean (median: lower, upper quartile). The serum levels were within normal limits in all cases.

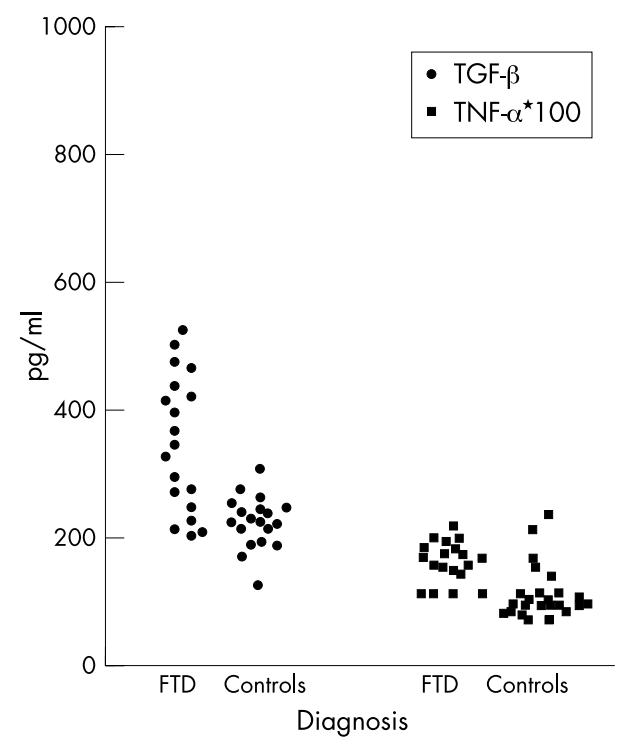

Figure 1 Plot of CSF TGF- $\beta$ and TNF- $\alpha$ in FTD and controls.

\section{DISCUSSION}

Increases in both TNF- $\alpha$ and TGF- $\beta$ were found in the CSF of FTD patients compared with controls. The increases in these cytokines were not related to a disturbance of blood-brain barrier function or leakage through the blood-brain barrier, nor were they related to differences in age or gender. Furthermore, the increases in the CSF were not due to increased systemic levels, as no correlation was found between the CSF and serum levels of the cytokines. Instead, the increases in CSF TNF- $\alpha$ and TGF- $\beta$ may reflect an increased intrathecal immunoactivity in FTD. The underlying cause of this increase is largely unknown. Increased CSF TNF- $\alpha$ is not related to brain damage such as stroke, ${ }^{30}$ but it is increased in dementia disorders ${ }^{22}$ in which inflammatory changes occur. ${ }^{15-19}$ TNF- $\alpha$ is produced by several cell types in the CNS, for example macrophages, astrocytes, and microglia. ${ }^{31}$ It is also pro-inflammatory. It acts as a tissue destructive protein and can induce apoptosis. It has also been shown to protect neurones from the toxic effects of $\beta$-amyloid, ${ }^{32}$ the central peptide in neuritic plaques. ${ }^{33}$ Thus, the increase may both lead to tissue destruction and have protective effects in the brains of FTD patients.

TGF- $\beta$ is a pleiotropic cytokine; its cellular sites of synthesis and targets are widely distributed throughout the body, including the CNS. Within the CNS, TGF- $\beta$ is produced by both glial and neuronal cells. ${ }^{34}$ The production of TGF- $\beta$ is regulated by other cytokines, including TNF- $\alpha{ }^{35}$ In the cytokine network, TGF- $\beta$ acts as an anti-inflammatory cytokine, inhibiting the production of pro-inflammatory cytokines such as TNF- $\beta$, IL- 1 , and IL- 6 by astrocytes, ${ }^{36}{ }^{37}$ and suppressing the activation and proliferation of microglia. ${ }^{37}$ Thus, in patients with FTD, the increased levels of TNF- $\alpha$ may trigger the production of TGF- $\beta$ by a negative feedback mechanism and counteract the pro-inflammatory effects of TNF- $\alpha$. The increase in CSF TGF- $\beta$ is thus related to an activation of inflammatory mechanisms and, as the bloodbrain barrier seems to have been intact and there was no systemic overproduction in these patients, this increase in CSF TGF- $\beta$ is intrathecal-that is, derived from the brain.

In FTD, a common change is mild gliosis of the white matter. $^{38}{ }^{39}$ Gliosis involves astrocytes, and there is a functional relationship between gliosis, astrocytosis, and changes in the CBF in FTD. ${ }^{40}$ Astrocytosis is also related to activation of apoptotic mechanisms. ${ }^{41}$ Based on histological findings that microglial activity is largely confined to the white matter in frontal lobe degeneration, some investigators argue that FTD is probably a white matter disease. ${ }^{42}$ An exception is the FTD subtype, Pick's disease, in which

\begin{tabular}{|c|c|c|c|c|}
\hline \multirow[b]{2}{*}{ Parameter measured } & \multicolumn{4}{|c|}{ Degree of atrophy/WMC } \\
\hline & 0 & 1 & 2 & 3 \\
\hline \multicolumn{5}{|l|}{ Cortex } \\
\hline Frontal & 1 & 5 & 8 & 1 \\
\hline Temporal & 1 & 3 & 10 & 1 \\
\hline Parietal & 9 & 3 & 3 & 0 \\
\hline Occipital & 13 & 2 & 0 & 0 \\
\hline \multicolumn{5}{|l|}{ Atrophy } \\
\hline Frontal central & 4 & 8 & 3 & 0 \\
\hline Posterior central & 9 & 5 & 1 & 0 \\
\hline \multicolumn{5}{|l|}{ WMC } \\
\hline Frontal & 11 & 4 & 0 & 0 \\
\hline Paraventricular/parietal & 13 & 2 & 0 & 0 \\
\hline Occipital & 14 & 1 & 0 & 0 \\
\hline
\end{tabular}


microglial activity is more widespread. These WMC may be related to increased inflammatory activity, and the increase in the CSF levels of the cytokines may be a reflection of that. In the present study, no relationship was found between WMC and the CSF levels of the cytokines. A possible explanation is that WMC were uncommon in this group of FTD patients.

The present study has some weaknesses. Firstly, there was no neuropathological confirmation of the FTD cases. Thus, some of these cases may have been misdiagnosed as frontal $\mathrm{AD}^{43}$ or some other neurodegenerative disorder. However, there are strong arguments in favour of the notion that clinical diagnosis of FTD can based on consensus criteria alone. ${ }^{2}$ Moreover, frontal AD is very uncommon, ${ }^{43}$ especially at those ages studied in the present study. Secondly, it is not known how many of the FTD cases included were due to tau gene mutations. However, this type of mutation is uncommon in the FTD population ${ }^{13} 44$ and was also found to be uncommon among our FTD patients. ${ }^{44}$ Thirdly, although inflammatory mechanisms most probably are involved in the pathogenesis of FTD, it is not known at what stage they become active participants. Inflammation may be a primary event in the pathophysiology of frontal lobe degeneration of non-Alzheimer type or it may be secondary to other changes. Fourthly, although increases in CSF cytokine levels in FTD were shown in the present study, it is not known what event or intracerebral changes they correspond to. These putative weaknesses must be taken into consideration when interpreting the results and when designing future studies of inflammatory markers in FTD.

\section{CONCLUSIONS}

Taken together, this study found evidence for increased levels of the inflammatory cytokines TNF- $\alpha$ and TGF- $\beta$ in the CSF of FTD patients compared with controls. This increase was not due to differences in age or gender, nor to leakage through the blood-brain barrier. Neither was it due to a systemic overproduction, but is intrathecal. Although these changes are not specific for FTD, they suggest that inflammatory mechanisms are part of the pathophysiological mechanisms that lead to FTD.

\section{ACKNOWLEDGEMENTS}

This work was supported by grants from Martina och Wilhelm Lundgrens Stiftelse, Stiftelsen för Gamla Tjänarinnor, Stiftelsen Handlanden Hjalmar Svenssons Forskningsfond, Pfannenstills forskningsfond, the Swedish Association of Neurologically Disabled, the Swedish Medical Society, and the Swedish Medical Research Council (grants \# 11560 and 12103). We are grateful to E Styrud and M Verdrengh for technical assistance.

\section{Authors' affiliations}

M Sjögren, S Folkesson, K Blennow, Institute of Clinical Neuroscience, Göteborg University, Sweden

E Tarkowski, Departments of Rheumatology, Göteborg University,

Sweden

E Tarkowski, Geriatrics, Göteborg University, Sweden

Competing interests: none declared

\section{REFERENCES}

1 Tissot R, Constantinidis J, Richard J. Pick's disease. In: Bruyn Va, ed. Handbook of clinical neurology. Amsterdam: North-Holland Publishing Company, 1985:233-46.

2 Gustafson L. Clinical picture of frontal lobe degeneration of non-Alzheimer type. Dementia 1993;4:143-8.

3 Knopman DS. Overview of dementia lacking distinctive histology: pathological designation of a progressive dementia. Dementia 1993;4:132-6.

4 Neary D, Snowden J. Fronto-temporal dementia: nosology, neuropsychology, and neuropathology. Brain Cogn 1996;31:176-87.
5 Sjögren M, Rosengren L, Minthon L, Davidsson P, Blennow K, Wallin A. Cytoskeleton proteins in CSF distinguish frontotemporal dementia from $A D$. Neurology 2000;54:1960-4.

6 Siögren M. The pathophysiology of frontotemporal dementia - cytoskeleton abnormalities and autoimmunity? Brain Aging 2002;2:18-26.

7 Delacourte A, Buée L, Vermersch P. Immunochemistry in frontotemporal dementia. In: Pasquier F, Lebert F, Scheltens $P$, eds. Fontotemporal dementia. Dordrecht: ICG Publications, 1996:115-24.

8 Siögren M, Minthon L, Davidsson P, et al. CSF levels of tau, beta-amyloid(142) and GAP-43 in frontotemporal dementia, other types of dementia and normal aging. I Neural Transm 2000;107:563-79.

9 Siögren M, Davidsson P, Tullberg M, et al. Both total and phosphorylated tau are increased in Alzheimer's disease. J Neurol Neurosurg Psychiatry $2001 ; 70: 624-30$

10 Green AJ, Harvey RJ, Thompson EJ, et al. Increased tau in the cerebrospinal fluid of patients with frontotemporal dementia and Alzheimer's disease Neurosci Lett 1999;259:133-5.

11 Mecocci P, Cherubini A, Bregnocchi M, et al. Tau protein in cerebrospinal fluid: a new diagnostic and prognostic marker in Alzheimer disease? Alzheimer Dis Assoc Disord 1998;12:211-14.

12 Hutton M, Lendon CL, Rizzu P, et al. Association of missense and 5'-splice-site mutations in tau with the inherited dementia FTDP-17. Nature 1998;393:702-5.

13 Houlden H, Baker M, Adamson J, et al. Frequency of tau mutations in three series of non-Alzheimer's degenerative dementia. Ann Neurol 1999:46:243-8.

14 Fabre SF, Forsell C, Viitanen M, et al. Clinic-based cases with frontotemporal dementia show increased cerebrospinal fluid tau and high apolipoprotein $E$ epsilon4 frequency, but no tau gene mutations. Exp Neurol 2001;168:413-18.

15 Dahlstrom A, McRae A, Polinsky R, et al. Alzheimer's disease cerebrospinal fluid antibodies display selectivity for microglia. Investigations with cell cultures and human cortical biopsies. Mol Neurobiol 1994;9:41-54.

16 Breitner JC. Inflammatory processes and antiinflammatory drugs in Alzheimer's disease: a current appraisal. Neurobiol Aging 1996;17:789-94.

17 Hull M, Strauss S, Berger M, et al. The participation of interleukin-6, a stressinducible cytokine, in the pathogenesis of Alzheimer's disease. Behav Brain Res 1996;78:37-41.

18 Pasinetti GM. Inflammatory mechanisms in neurodegeneration and Alzheimer's disease: the role of the complement system. Neurobiol Aging 1996; 17:707-16.

19 Velazquez P, Cribbs DH, Poulos TL, et al. Aspartate residue 7 in amyloid betaprotein is critical for classical complement pathway activation: implications for Alzheimer's disease pathogenesis. Nat Med 1997;3:77-9.

20 Tarkowski E, Liljeroth AM, Nilsson A, et al. Decreased levels of intrathecal interleukin 1 receptor antagonist in Alzheimer's disease. Dement Geriatr Cogn Disord 2001;12:314-17.

21 Tarkowski E, Issa R, Sjogren M, et al. Increased intrathecal levels of the angiogenic factors VEGF and TGF-beta in Alzheimer's disease and vascular dementia. Neurobiol Aging 2002;23:237-43.

22 Tarkowski E, Blennow K, Wallin A, et al. Intracerebral production of tumor necrosis factor-alpha, a local neuroprotective agent, in Alzheimer disease and vascular dementia. J Clin Immunol 1999;19:223-30.

23 Tarkowski E. Cytokines in dementia. Curr Drug Targets Inflam Allergy 2002; 1:197-204.

24 Marcinkowski T. The diseases of Alzheimer and Pick from the viewpoint of prevention. Med Hypotheses 1996:46:180-2.

25 Sjogren M, Wallin A. Pathophysiological aspects of frontotempora dementia-emphasis on cytoskeleton proteins and autoimmunity. Mech Ageing Dev 2001;122:1923-35.

26 American Psychiatric Association. Diagnostic and statistical manual of mental disorders, revised, 3rd ed Washington DC: Cambridge University Press, 1987

27 Neary D, Snowden JS, Gustafson L, et al. Frontotemporal lobar degeneration: a consensus on clinical diagnostic criteria. Neurology 1998;51:1546-54.

28 Sjögren M, Edman $\AA$, Wallin A. Symptomatological characteristics distinguish between frontotemporal dementia and vascular dementia with a dominant frontal lobe syndrome. Int J Geriatr Psychiatry 1997; 12:656-61

29 Sï̈gren $M$, Blomberg $M$, Jonsson $M$, et al. Neurofilament protein in cerebrospinal fluid: a marker of WMC. J Neurosci Res 2001;66:510-16.

30 Tarkowski E, Rosengren L, Blomstrand C, et al. Intrathecal release of pro- and anti-inflammatory cytokines during stroke. Clin Exp Immunol 1997; 110:492-9

31 Righi M, Mori L, De Libero G, et al. Monokine production by microglial cell clones. Eur J Immunol 1989;19:1443-8.

32 Barger SW, Horster D, Furukawa K, et al. Tumor necrosis factors alpha and beta protect neurons against amyloid beta-peptide toxicity: evidence for involvement of a kappa B-binding factor and attenuation of peroxide and $\mathrm{Ca}^{2+}$ accumulation. Proc Natl Acad Sci USA 1995;92:9328-32.

33 Gowing $E$, Roher AE, Woods AS, et al. Chemical characterization of $A$ beta 17-42 peptide, a component of diffuse amyloid deposits of Alzheimer disease. J Biol Chem 1994;269:10987-90.

34 Pratt BM, McPherson JM. TGF-beta in the central nervous system: potential roles in ischemic injury and neurodegenerative diseases. Cytokine Growth Factor Rev 1997;8:267-92.

35 Tracey KJ, Cerami A. Tumor necrosis factor: a pleiotropic cytokine and therapeutic target. Annu Rev Med 1994;45:491-503.

36 Benveniste EN, Tang LP, Law RM. Differential regulation of astrocyte TNFalpha expression by the cytokines TGF-beta, IL-6 and IL-10. Int J Dev Neurosci 1995; 13:341-9. 
37 Suzumura A, Sawada M, Yamamoto $\mathrm{H}$, et al. Transforming growth factorbeta suppresses activation and proliferation of microglia in vitro. J Immunol beta suppresses activa

38 Brun A, Passant U. Frontal lobe degeneration of non-Alzheimer type. Structural characteristics, diagnostic criteria and relation to other frontotemporal dementias. Acta Neurol Scand Suppl 1996;168:28-30.

39 Odawara T, Iseki E, Kanai A, et al. Clinicopathological study of two subtypes of Pick's disease in japan. Dement Geriatr Cogn Disord 2003;15:19-25.

40 Martin JA, Craft DK, Su JH, et al. Astrocytes degenerate in frontotemporal dementia: possible relation to hypoperfusion. Neurobiol Aging 2001;22:195-207.
41 Su JH, Nichol KE, Sitch T, et al. DNA damage and activated caspase-3 expression in neurons and astrocytes: evidence for apoptosis in frontotemporal dementia. Exp Neurol 2000;163:9-19.

42 Cooper PN, Siddons CA, Mann DM. Patterns of glial cell activity in frontotemporal dementia (lobar atrophy). Neuropathol Appl Neurobiol 1996;22:17-22.

43 Brun A. Frontal lobe degeneration of non-Alzheimer type revisited. Dementia 1993;4:126-131

44 Froelich Fabre S, Forsell C, Viitanen $M$, et al. Clinic-based cases with frontotemporal dementia show increased cerebrospinal fluid tau and high apolipoprotein E varepsilon4 frequency, but no tau gene mutations. Exp Neurol $2001 ; 168: 413-18$.

\section{HISTORICAL NOTE}

\section{William John Adie (1886-1935)}

W liam John Adie is best known for his account of the tonic pupil, a physical finding of a dilated pupil that reacts poorly to light but better to accommodation. The reaction of the pupil is sluggish and is usually unilateral, most often seen in women, commonly with absent leg tendon reflexes. ${ }^{12}$ The pathology is now localised to the ciliary ganglion. The preserved response of the pupil to accommodation results from the higher percentage of fibres from the ciliary ganglion that innervate the iris for accommodation than for constriction to light.

Adie described 19 patients, 13 with absent tendon reflexes, and noted 44 reported cases of tonic pupil. In an exemplary clinical essay, he outlined four incomplete forms (the last would not now be accepted):

1) The complete form-typical tonic pupil and absence of reflexes

2) Incomplete forms: a) tonic pupil alone; b) atypical phase of the tonic pupil alone (iridoplegia; internal ophthalmoplegia); c) atypical phases of the tonic pupil with absent reflexes; and d) absent reflexes alone.

Adie did not claim originality, recognising descriptions from 1902. However, James Ware in 1813 and Hughlings Jackson in 1881 both provided convincing accounts; ${ }^{3}$ Gordon Holmes described the same disorder in $1931^{4}$ but is surprisingly not acknowledged in Adie's Brain paper. ${ }^{2}$

William John Adie was born in Geelong, west of Melbourne on the southern Australian coast. He was educated at Flinder's School, but at the age of 13 had to leave in order to support the family, as his father had died in 1899. He worked as an office errand boy. One of his employers recognised his abilities and paid for his tuition. Thus he passed the examination for university entry. Dr Arthur South in Geelong inspired Adie to embark on a medical career, but medical school fees in Melbourne were high and an uncle paid for his $£ 19$ one way ticket to England. He obtained a scholarship that enabled him to read medicine at Edinburgh, where he graduated in 1911. He then visited German clinics and returned to the National Hospital, Queen Square, as house physician.

At the outbreak of world war one Adie joined the Northamptonshire Regiment and served as medical officer in France, where he took part in the retreat from Mons, although his regiment was annihilated. He was transferred to the Leicestershire Regiment and saw active service. In 1916 he was mentioned in despatches for saving a number of soldiers in one of the early gas attacks by improvising a mask of clothing soaked in urine. He subsequently took charge of the 7th General Hospital, and also acted as a consultant in the management of head injuries. ${ }^{5}$
After the war he became medical registrar at Charing Cross Hospital, London. In 1916 he married Lorraine Bonar; they had a daughter and a son. He was appointed to the staff of the National Hospital, Queens Square, and Moorfields Eye Hospital. His clinical acumen and diagnostic skill were soon evident; his teaching was also much in demand. With Macdonald Critchley he described in frontal lobe disease "a syndrome of forced grasping and groping". ${ }^{6}$ He lucidly described narcolepsy, ${ }^{7}$ and wrote important papers on pituitary tumours and disseminated sclerosis. With James Collier, he wrote the section on neurology in Price's Textbook of medicine, generally considered the finest general textbook account of neurology.

He earned several honours. The University of Edinburgh awarded him their gold medal and he was a founder of The Association of British Neurologists (ABN). The ABN was initiated at a meeting in the house of Gordon Holmes at 9 Wimpole Street, on 28 July 1932. Present were: WJ Adie, E Bramwell, EF Buzzard, H Cohen, JS Collier, DE Core, A Feiling, RG Gordon, JG Greenfield, G Hall, W Harris, W Johnson, FJ Nattrass, C Worster-Drought, SA Kinnier Wilson, and G Holmes.

Sadly, when aged 45 Adie developed angina and in 1935 was obliged to resign his post when only 48 . He died from a myocardial infarct on 17 March 1935.

Adie was admired for his intelligence and powers of shrewd clinical observation. Above all, he was esteemed as a modest generous man loved by his students. He was a keen bird watcher and tennis player. In his native town, the youth who had accomplished so much on the other side of the world was not forgotten. The daily newspaper, Geelong Advertiser, headed a long obituary: "Geelong boy who made good in London".

J M S Pearce

304 Beverley Road, Anlaby, Hull HU10 7BG, UK; imspearce@freenet.co.uk

\section{References}

1 Adie WJ. Pseudo-Argyll Robertson pupils with absent tendon reflexes. A benign disorder simulating tabes dorsalis. British Medical Journal $1931 ; 1: 928-30$.

2 Adie WJ. Tonic pupils and absent tendon reflexes: a benign disorder sui generis; its complete and incomplete forms. Brain 1932;55:98-113.

3 Pearce JMS. Hughlings Jackson and the Holmes-Adie tonic pupil. In: Fragments of neurological history. London: Imperial College Press, 2003

4 Holmes G. Partial iridoplegia associated with symptoms of other diseases of the nervous system. Trans ophthal Soc 1931;51:209-28.

5 Adie WJ, Wagstaffe WW. A note on a series of 656 cases of gunshot wound of the head, with a statistical consideration of the results obtained. Medical Research Committee Statistical Reports, no. 1. London: Stationery Office, 1918.

6 Adie WJ, Critchley M. Forced grasping and groping. Brain 1927;50:142-70.

7 Adie WJ. Idiopathic narcolepsy: a disease sui generis: with remarks on the mechanism of sleep. Brain 1926;49:275-306. 